\title{
Trajectories of Psychological Adaptation to Marital Breakup after a Long-Term Marriage
}

\author{
Bina Knöpfli ${ }^{a}$ Davide Morsellib Pasqualina Perrig-Chiello ${ }^{a}$ \\ ${ }^{a}$ Department of Psychology, University of Bern, Bern, and ${ }^{b}$ Institute of Social Sciences, University of Lausanne, \\ Lausanne, Switzerland
}

\section{Key Words}

Divorce · Long-term marriage · Middle and old age .

Psychological adaptation - Resources · Latent transition analysis · Personality · Resilience

\begin{abstract}
Background: Marital dissolution is known to be among the most stressful life events with long-reaching negative consequences on individuals' lives. A limitation in research to date is that most studies have focused on the impact of marital disruption on well-being outcomes in younger adults. Furthermore, although population-based studies on divorce document a broad range of negative effects, more finegrained analyses reveal a large heterogeneity in people's adjustment, which is still not well understood. Objective: The aim was to explore trajectories of psychological adaptation to marital breakup after a long-term marriage, and to examine variables accounting for recovery or chronicity in terms of intrapersonal resources (personality, trait resilience, and personal growth), relationship variables (satisfaction with ex-relationship, length of marriage, and time since divorce), and sociodemographic variables (age, gender, and financial situation). Methods: Latent transition analysis is used to examine the course of psychological adaptation (i.e., depressive symptoms, life satisfaction, hopelessness, mourning,
\end{abstract}

and subjective health) to divorce over 2 years among 5 profiles of 308 divorcees (mean age: 55.6 years; average duration of former marriage: 23.62 years). We present two larger groups of individuals, one of which adapted very well ('resilients', 29\%) and the other quite well ('average copers', 49\%), as well as three groups with major difficulties ('vulnerables', $6 \%$; 'malcontents', $12 \%$, and 'resigned', $4 \%$ ). In a second step, the differences between transition patterns were explored on the basis of the distal variables (i.e., intrapersonal resources, relationship variables, and sociodemographics). Results: Although the probability of upward changes was higher for those individuals with lower adaptation at time point 1 , only a small number of individuals made an upward change from the maladapted to the well-adapted groups throughout the 2 years. The groups of copers and resilients remained stable in their psychological adaptation. The most consistent results related to upward changes were intrapersonal resources, namely the NEO personality traits and trait resilience. Conclusion: The majority of individuals divorcing after a long-term marriage adapt successfully over time. Adaptation trajectories depend primarily on intrapersonal resources. However, a minority of divorcees exhibit enduring difficulties. Knowledge about the diversity of these trajectories of vulnerability could be of great help for designing psychological interventions to better tackle this critical life event.

(c) 2016 S. Karger AG, Basel

\section{KARGER}

E-Mail karger@karger.com

www.karger.com/ger
(C) 2016 S. Karger AG, Basel

0304-324X/16/0000-0000\$39.50/0
Bina Knöpfli

Department of Psychology, University of Bern

Fabrikstrasse 8

CH-3012 Bern (Switzerland)

E-Mail bina.knoepfli@psy.unibe.ch 


\section{Introduction}

Marital dissolution is known to be among the most stressful life events $[1,2]$. Although population-based studies on divorce document a broad range of negative effects, more fine-grained analyses reveal a large heterogeneity in people's adjustment, which is still not well understood [2]. In fact, several prospective and longitudinal studies report that after a short-term decline in well-being, most individuals recover $[3,4]$, but a significant minority remains seriously troubled $[2,5]$. Identifying variables that account for the strength and duration of divorce effects over time is still a relevant research topic [2]. This is especially the case for divorce after a long-term marriage. Actually, most research focused on the impact of marital disruption on well-being outcomes in younger adults [6]. Considering the significant increase in divorce rates among adults aged 50 years and older quitting a long-term marriage, this research gap is especially regrettable. In the USA, as in most European countries, the divorce rate in this age group has doubled in the last 20 years [7]. In Switzerland, where the present study was conducted, the divorce rate for marriages lasting longer than 20 years has risen from $15 \%$ in 1970 to $28 \%$ in 2010 [8].

However, the role of the duration of marriage, especially a longer duration, has hardly been considered in divorce research. The few studies that included this factor suggest that the length of a marriage proves predictive of more stress symptoms [9]. Strongly related to the duration of marriage is age. It is known that the age at which one experiences a critical life event can shape both the nature of the event as well as the individual's subsequent adjustment [10]. For individuals in later adulthood, divorce may be accompanied by some of the challenges that younger persons face, but also by a set of distinctive agerelated risks as well as resources [10]. In fact, there is some evidence that the negative effect of marital breakup is strongest in younger age groups [11]; however, other studies found the opposite [12] and these findings suggest that recovering from divorce is more difficult in later years, as growing older increases the importance of having an intimate relationship in times of decreasing physical and social resources.

Considering these research gaps, the aim of the present paper is to shed light on various trajectories of psychological adaptation to marital breakup among individuals who had been married for more than 20 years, and to explore the factors that contribute to recovery or chronicity.
Trajectories of Psychological Adaptation to Divorce

Recent research has emphasized the substantial degree of heterogeneity in long-term stress responses to critical life events including divorce. Recovery generally connotes a pattern in which normal life functioning is interrupted and depressive symptoms and distress endure for several months and then gradually return to baseline (generally after 2 years) [13]. However, this pattern does not fit all individuals concerned. One of the first studies focusing on the diversity in adjustment to divorce is a longitudinal study with 6 annual waves carried out by Hetherington [14]. Results of cluster analyses (based on 11 variables such as subjective health, depression, and life satisfaction) revealed that 6 years after divorce, one fifth of the study participants were very well adjusted to their new situation, whereas $10 \%$ were still hopeless and depressed. The remaining majority adapted quite well and had average scores for most outcomes. In the same vein, Mancini et al. [15] investigated the course of adaptation to critical life events ( 4 years before and 4 years after events such as divorce or bereavement) in the first 20 annual waves of the German Socioeconomic Panel. Results of latent growth mixture modelling provided a three-class solution for the sample of divorcees, which consisted of 629 participants. There was a large group of 'resilient' individuals (71.8\%) who showed a stable level of life satisfaction despite the event. A second group exhibited a change from moderate to decreased scores (19.1\%), and the third group from low to increased life satisfaction (9.1\%). In contrast, Infurna and Luthar [16], who used the same data of the German Socioeconomic Panel as Mancini et al. [15] but applied different statistical model specifications, found a significantly lower rate of resilients, namely only $36 \%$. The authors conclude that resilience has been overestimated in previous studies and that further longitudinal studies are needed using a wider range of adaptation indicators [16].

\section{Stressors and Resources Predicting Adaptation to Marital Breakup}

Independently of the exact rate of resilients, it still remains a fact that there are significant differences in adaptation to divorce between groups. A prominent theoretical approach to explaining these differences, which we rely on in this kind of research, is the divorce-stress-adjustment perspective [17]. This approach considers marital dissolution as a process typically associated with various stressors that increase the risk of psychological distress and negative health outcomes [2]. The severity and duration of negative outcomes resulting from divorce- 
induced stressors depend on the presence of a variety of moderating or protective factors such as personal and social resources.

The most studied stressors are related to the time before breakup (e.g., dissatisfaction with former relationship) as well as after it (e.g., financial strain [18]). Regarding the impact of the quality of the ex-marriage, studies revealed mixed findings. Although some studies suggest that persons from low-distress marriages have more difficulties in adapting than those from high-distress ones [19], other studies could not replicate these findings [20].

The effects of divorce-induced stress can be moderated by protective factors or resources. There is increasing empirical evidence that intrapersonal resources like personality traits play a central role in the process of adaptation to marital dissolution. Individuals with low scores in neuroticism and high scores in openness and extraversion seem to adapt better to marital breakup [10]. Another personality dimension that has been discussed as a protective factor in case of critical life events is trait resilience, which refers to the ability to maintain relatively stable, healthy levels of psychological and physical function in the face of disruptive events $[4,21]$.

A further possible resource that has seldom been investigated so far in divorce research is personal growth following the event. In fact, very few studies have investigated the possibility of positive life changes following relationship breakups [22]. Stress-related growth refers to the notion that people can grow beyond their previous level of psychological functioning in response to a distressing or traumatic life event through being mindful and by experiencing a new meaning of life [23].

\section{Research Aims and Hypotheses}

The present paper aims at exploring trajectories of psychological adaptation to marital breakup after a longterm marriage. It builds upon results from exploratory latent profile analyses (LPA) carried out in the first wave of a longitudinal project with 308 individuals (mean age: 55.6 years) [6]. The classification variables considered affective (depression, hopeless, and mourning) and cognitive (life satisfaction) dimensions of well-being as well as subjective health. The inclusion of several indicators of psychological adaptation is in accordance with empirical research showing that suffering from critical life events may have differential effects upon the various dimensions of well-being [24], and that research based on single indicators of well-being disregards the multidimensionality of well-being [16]. LPA of the first-wave data of this study revealed five profiles of adaptation to divorce: two classes

Trajectories of Adaptation to Marital Breakup of very well ('resilients', 29\%) and well-adapted individuals ('average copers', 49\%), and three groups with major difficulties ('resigned', 4\%; 'malcontents', 12\%; 'vulnerables', 6\%) [6]. The latter three groups reported the lowest rates in all measures of adaptation. In contrast, the 'resilient' group included the respondents with the highest scores in life satisfaction and subjective health and the lowest scores in hopelessness, mourning, and depressive symptoms. The largest group, the 'average copers', revealed mean scores closest to the overall sample mean. Discriminant variables between the groups primarily were personality traits, time since separation, a new relationship, and the financial situation. Age, gender, and length of marriage played a marginal role; satisfaction with the former marriage and initiator status were not relevant.

In this paper, we wanted to explore the stability or upward changes of these profiles 2 years later, at wave 2 . In addition, we aimed to examine the variables that account for stability and change in terms of personality variables [NEO personality traits (neuroticism, extraversion, openness), trait resilience, and personal growth], relationship variables (marital satisfaction, length of relationship, and years since divorce), and sociodemographic variables (age, gender, and financial situation). Based on the divorce-stress-adjustment perspective [17] and considering results from resilience research $[4,13]$, we expected an upward change for a substantial number of individuals with the three profiles of poor adaption (i.e., resigned, malcontents, and vulnerables). These upward changes are expected to be associated with decreasing relationship stressors over time (i.e., less financial strains), especially in those with better intrapersonal resources (higher openness, extraversion, trait resilience, and personal growth; lower neuroticism). Because of the limited and inconsistent results to date, we did not have any specific expectations regarding age and length of the relationship. With regard to the well-adapted individuals (average copers and resilients), we expect that they would remain at a stable positive well-being level, since due to the better resources and fewer stressors, they had already reached their optimal level of functioning.

\section{Methods and Measures}

Study Context and Participants

The data presented stem from a longitudinal, survey-based study with two measurement points (2012 and 2014). The study aimed at gaining insight into the trajectories of psychological adaptation to marital breakup in the second half of life, be it the result 
of divorce or bereavement, and was approved by the Ethics Committee at the University of Bern. For this paper, only the divorced group is considered. Based on a random sample supplied by the Swiss Federal Office of Statistics and stratified by age group, gender, and marital status, a total of 1,082 persons aged between 45 and 65 years who had been divorced within the previous 5 years (independent individuals, not ex-couples) were contacted by mail and asked to participate in a survey. Nonrespondents were recontacted twice; the return rate was $42.8 \%(\mathrm{n}=422)$. In this study, we focus on individuals who had been married for 15 and more years prior to the divorce in order to ensure a more homogenous sample of the long-term married, thereby allowing clearer conclusions. At the first wave of data gathering (T1), 308 persons fulfilled this criterion. The sample consisted of 113 men (mean age $\mathrm{T}_{\mathrm{T} 1}=56.18$ years; $\left.\mathrm{SD}_{\mathrm{T} 1}=5.80\right)$ and 195 women (mean age $\mathrm{T}_{1}=54.95$ years; $\mathrm{SD}_{\mathrm{T} 1}=$ 5.33). The average length of the marriage was 23.62 years (range: $15-40)$; the average time since the divorce was 2.88 years ( range $_{\mathrm{T} 1}$ : $0.6-5$ years).

As stated above, the 308 participants were split up into five profiles of adaptation [6]: 'average copers' $(n=151)$, 'resilients' ( $n=$ $90)$, 'vulnerables' $(n=18)$, 'malcontents' $(n=37)$, and 'resigned ones' $(\mathrm{n}=12)$. Two years later $(\mathrm{T} 2)$, the sample was recontacted and received the same questionnaire as at T1. The participation rate was $86.3 \%(n=266)$.

Outcome Variables: Indicators of Psychological Adaptation

Life satisfaction was assessed with the Satisfaction with Life Scale [25], consisting of 5 items with answers on a 7-point scale $\left(1=\right.$ 'completely disagree' to $7=$ 'completely agree'; mean $_{\mathrm{T} 1}=4.83$, $\left.\mathrm{SD}_{\mathrm{T} 1}=1.23\right)$ and loading onto one factor. The internal reliability was $\alpha=0.87$.

Depression was measured with the Center of Epidemiologic Studies Depression Scale [26], consisting of 15 items $\left(\operatorname{mean}_{\mathrm{T} 1}=\right.$ $0.59, \mathrm{SD}_{\mathrm{T} 1}=0.50$; answers on a 4 -point scale: $0=$ 'not at all', $3=$ 'all the time'). The scale displayed excellent internal reliability ( $\alpha=$ $0.90)$.

Hopelessness was measured with a short version of the Beck Hopelessness Scale [27]. The 10 items (answer scale: 1 = 'very much untrue' to $6=$ 'very much correct') assess the negative expectations of persons concerning themselves, their environment, and their future $\left(\operatorname{mean}_{\mathrm{T} 1}=2.62, \mathrm{SD}_{\mathrm{T} 1}=0.73 ; \alpha=0.83\right)$.

Subjective health was assessed with the widely used single-item question: 'How are you presently doing health-wise?' The answer options range from $1=$ 'very well' to $5=$ 'very badly' $\left(\operatorname{mean}_{\mathrm{T} 1}=\right.$ $\left.2.01, \mathrm{SD}_{\mathrm{T} 1}=0.88\right)$.

Mourning was measured with a self-developed item about whether the participants mourned the loss of their partner. The answer options ranged from 1 = 'yes very much', 2 = 'sometimes', and $3=$ 'no' to $4=$ 'no, rather the opposite' $\left(\operatorname{mean}_{\mathrm{T} 1}=2.64, \mathrm{SD}_{\mathrm{T} 1}=0.91\right)$.

\section{Distal Variables: Intrapersonal Resources}

Personality was assessed with the Big Five Inventory [28], consisting of 2 items for each of the 5 personality dimensions. Each item can be scored on a scale from $1=$ 'disagree strongly' to $5=$ 'agree strongly'. Based on previous findings, we focused only on the NEO dimensions with mean scores: neuroticism mean ${ }_{\mathrm{T} 1}=$ 2.64, $\mathrm{SD}_{\mathrm{T} 1}=0.93$; extraversion mean $_{\mathrm{T} 1}=3.32, \mathrm{SD}_{\mathrm{T} 1}=1.06$; openness mean $_{\mathrm{T} 1}=3.76, \mathrm{SD}_{\mathrm{T} 1}=0.96$.

Trait resilience was measured with the brief version of the Resilience Scale [29], a one-dimensional scale with 11 items (answer options ranging from $1=$ 'I don't agree' to 7 = 'I agree completely'; mean $\left._{\mathrm{T} 1}=5.54, \mathrm{SD}_{\mathrm{T} 1}=0.85\right)$, which correlates strongly with the full version of the Resilience Scale $(r=0.95)$ [29]. It demonstrated good internal consistency $(\alpha=0.86)$.

Personal growth was assessed with the short form of the Posttraumatic Growth Inventory (PTGI-SF), consisting of 10 items [30]. For this study, the original instruction, to indicate the degree of life change experienced 'as a result of your crisis', was specified 'as a result of the breakup' on a 6-point scale ( 1 = 'I did not experience this change', 6 = 'I experienced this change to a great degree'). Our analyses (confirmatory factor analysis) confirmed that a three-factor solution was a reasonable fit within the current sample $\left[\chi^{2}(31)=103.92, \mathrm{p}<0.001, \mathrm{CFI}=0.99, \mathrm{TLI}=0.98, \mathrm{RMSEA}=0.08\right.$, WRMR = 0.78]: (1) 'new life perspectives' (items 1, 2, 3, and 6 of the PTGI-SF; $\alpha=0.81$ ), (2) 'spiritual growth' (items 4 and 8 ; $\alpha=$ 0.91 ), and (3) 'personal strength' (items 5, 7, 9, and 10; $\alpha=0.77$ ).

\section{Possible Stressors Related to the Ex-Relationship}

Satisfaction with former relationship was measured with the question 'In general, how happy were you in this relationship?' answered on a 10-point scale from $1=$ 'very unhappy' to $10=$ 'very happy' $\left(\right.$ mean $\left._{\mathrm{T} 1}=5.84, \mathrm{SD}_{\mathrm{T} 1}=2.16\right)$.

Length of former relationship was assessed by also including the premarriage period ( mean $=26.05$ years; $\mathrm{SD}=6.19$; range: 15-47).

Time since divorce was considered to control for the role of time in psychological adaptation to the event $\left(\right.$ mean $_{\mathrm{T} 1}=2.88$ years; $\mathrm{SD}_{\mathrm{T} 1}=1.56$; range: $0.6-5$ ).

The analyses were also controlled for the respondents' gender, age, and self-declared financial situation (from $1=$ 'Not having enough money to support oneself' to $3=$ 'Having more than enough money to support oneself; $\operatorname{mean}_{\mathrm{T} 1}=1.99 ; \mathrm{SD}_{\mathrm{T} 1}=0.43$ ).

\section{Analytical Strategy}

To test the hypotheses, we used latent transition analysis in three steps. First, separate LPA was performed for each wave on the 5 outcome variables. Models were specified with unequal means and equal variance across groups. In this study, three types of indicators were used to assess the correct number of groups: the Bayesian information criterion (BIC), the bootstrapped likelihood ratio test (BLRT), and entropy. The BIC indicator offsets the fit of the model with the number of estimated parameters, assuming that a model is penalized by the number of estimated parameters. The best model is indicated by the lowest BIC. The BLRT indicates whether including one extra class in the analysis produces a significant (i.e., larger than 0 ) improvement in the model fit. The best fit is indicated by the last significant BLRT. Entropy gives information on the probability of respondents being classified into more than one cluster. Values of entropy near 1 indicate a high certainty of classification.

Following Nylund et al. [31], the second step focused on testing the best-fitting model of transition. After testing that the same number of profiles could be estimated at both waves, model 1 estimated the latent transition between the profiles at T1 and the profiles at T2, allowing the item-response means of the outcome variables to be different across waves. Model 2 tested the measurement invariance of the two sets of profiles, so that the profiles had the same configuration and the same interpretation at both time points. In this model, the item-response means were constrained to be equal across waves. In model 3, we tested the hypothesis that 
the profiles not only had equal meaning at both waves, but that they represented stages of psychological adaptation. In this model, the probability of backwards transitions was constrained to 0 . Members of a profile were allowed to move only to one of the more adapted profiles; thus, members of a maladapted profile could move to a more resilient one, but not vice versa. Model 4 extended model 3 and imposed that respondents could move only to the closest profile, i.e., the most similar means in the outcome variables.

In addition, an extra profile was inserted at T2, which included all respondents who had dropped out of the survey between the two waves. This dropout profile was added to all models. It had the advantage of allowing us to use the same sample size at T1 as Perrig-Chiello et al. [6] and allowed us to control that dropouts were randomly distributed between profiles and not more likely for some profiles than others (e.g., vulnerable respondents at T1). A comparison between models was used to test which hypothesis was better supported by the data. The BIC index was applied to determine the best-fitting model, and entropy was used for understanding the overall classification of respondents into the latent transition profiles.

In the third step of the analysis, distal variables were introduced into the best-fitting model to explore the difference between respondents who remained in the same profile and those who transitioned to another profile. This method is similar to the use of distal variables proposed by Lanza et al. [32] for cross-sectional latent class analysis (LCA). Lanza's method has the advantage over other methods that use covariates in the LCA (e.g., Clark and Muthén [33]) that it does not allow the distal variables to drastically change the composition of the profiles. The advantage of this procedure is to avoid imposing a profile membership on the respondents. LCA indeed treats the classification as a latent variable, and thus accounts for classification uncertainty. In other words, this analysis models the respondents' probability of being classified into all of the different profiles and estimates the difference between these profiles on the basis of the distal variables.

Our model followed the same logic but was applied to all latent transitions instead of class memberships. The model was estimated following the recommendations of Nylund-Gibson et al. [34] and Asparouhov and Muthén [35]. The profile probabilities for the most likely profile membership extracted from the LCA, run separately for each wave, were used to calculate the classification uncertainty rate, which is the average probability that members of each profile could also be classified into the other profiles. The classification uncertainty rate was computed as the logarithm of the proportion between the average probability of the most likely profile and the sum of the average probabilities of the other profiles [35]. Then the uncertainty rate was used to correct the classification of respondents into the profiles derived from the previous step, and to calculate the transitions from each profile at T1 to each profile at T2. Finally, distal variables were inserted in the model one at a time, and their means were estimated for each possible transition pattern. This last step computed the means of distal variables for respondents who were either classified into the same profile at both waves or classified into a different profile at T2. Estimation of the mean of the distal variables is based on the latent categorical variables estimated at T1 and T2; hence, respondents' classification into the profiles was corrected by classification uncertainty at each wave. This procedure had the advantage of avoiding a collapse of the classification error at both time points, as
Table 1. Fit indexes for tested T2 models

\begin{tabular}{llll}
\hline Profile No. & BIC & BLRT & Entropy \\
\hline 1 & $2,728.99$ & $-1,473.57^{* * *}$ & 0.91 \\
2 & $2,680.26$ & $-1,305.91^{* * *}$ & 0.75 \\
3 & $2,672.30$ & $-1,264.80^{* * *}$ & 0.78 \\
4 & $2,683.88$ & $-1,244.08^{*}$ & 0.78 \\
5 & $2,697.08$ & $-1,233.14$ & 0.81 \\
\hline \multicolumn{2}{c}{$* \mathrm{p}<0.05 ;$} & \\
\hline
\end{tabular}

would occur if the most likely profile for each respondent were considered as an observed variable instead of a latent classification.

Analyses were performed with Mplus 7.3 in combination with the MplusAutomation package for $\mathrm{R}$ [36]. The models were estimated using the maximum likelihood estimation with standard errors based on the first-order derivatives, as implemented in Mplus. To ensure that model results did not depend on local maxima, each final model was reproduced by increasing to 1,000 the number of random starts and to 100 the number of final-stage optimizations [37].

\section{Results}

\section{Latent Profiles of Responses to Divorce and Longitudinal Transitions}

At first, the number of profiles for each wave was investigated separately, based on the 5 outcome variables. For T1, the results replicated the ones by Perrig-Chiello et al. [6], indicating a 5-profile solution as preferable over the others. Concerning T2, the BIC indicator was lowest for the 4-profile model, whereas the last significant BLRT was given by the 5 -profile model (table 1). Entropy was equivalent in both models. Given that the BLRT was shown to perform better than other indicators in determining the number of profiles, and that the 5-profile solution would facilitate further analyses on transitions, we chose the model with 5 profiles over the one with 4 .

Once it had been determined that 5 was the appropriate number of profiles for both waves, we tested several latent transition models as described in the previous section. Model 1 (BIC index $=6,697.76$, entropy $=0.86$ ) was the unconstrained model and was used only as a reference to determine whether subsequent models fit the data better. Results are reported in table 2. To make the interpretation easier, profiles were sorted from the most vulnerable to the most resilient, following the study by Perrig-Chiello et al. [6]. The dropouts were evenly distributed among all profiles; the vulnerable profile at $\mathrm{T} 1$ 
Table 2. Transition probabilities of $\mathrm{T} 1$ profiles (rows) by $\mathrm{T} 2$ profiles (columns)

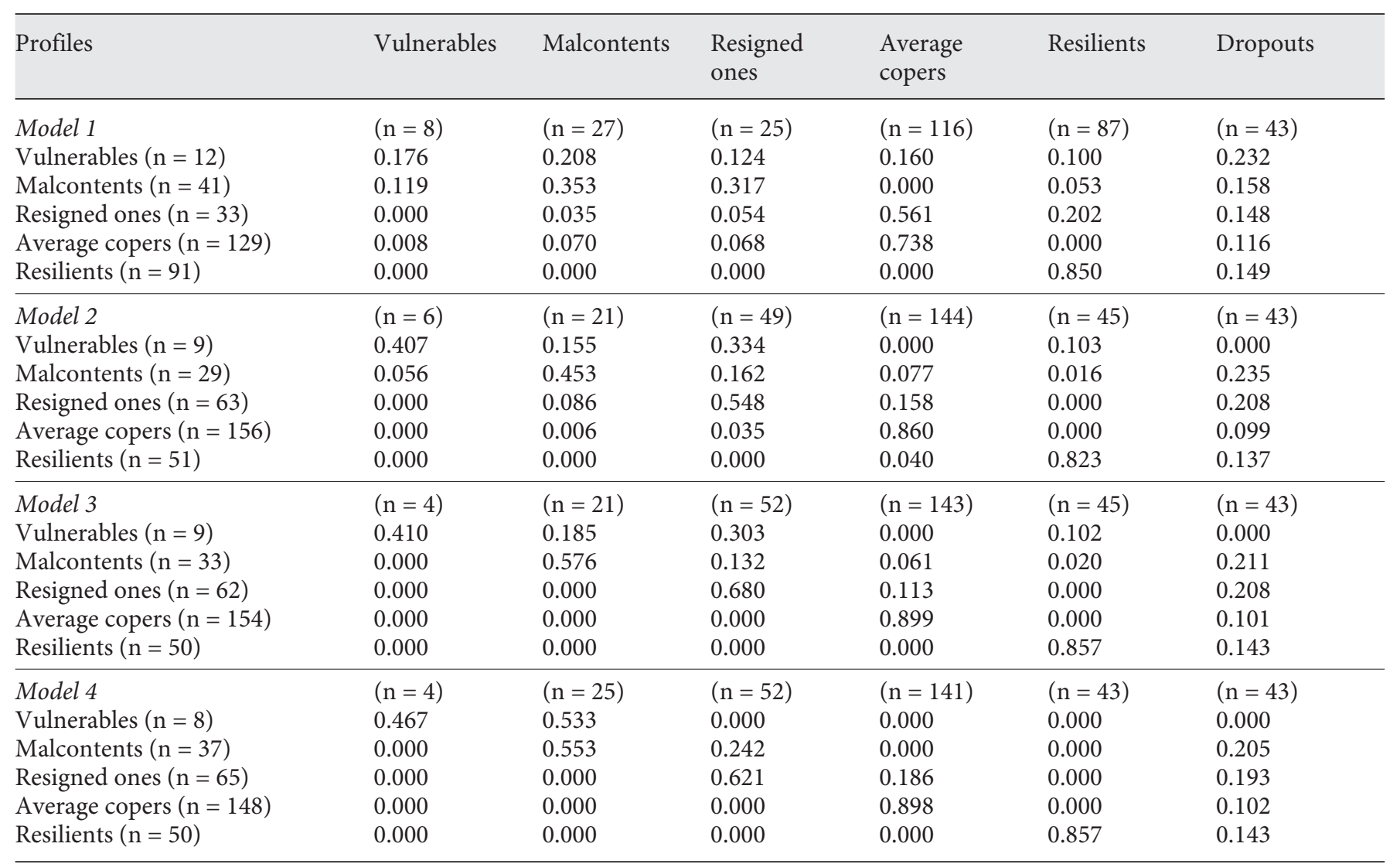

Profile counts are estimated on their most likely latent profile pattern; except for the dropout profile, which is observed, all other categories are estimated latent variables, and thus the individual probability of belonging to each profile can slightly change from model to model.

had a slightly higher percentage of dropouts, although this was most likely due to the small sample size in this category.

In model 2, the profile scores of the outcome variables were constrained to be equal across waves. The fit of model 2 (BIC index $=6,571.32$, entropy $=0.88$ ) was better than that of the unconstrained model, suggesting that the profiles had the same structure across the two time points. This solution has the advantage of making the interpretation of the transition easier, because the profiles of T1 and T2 represent the same pattern of responses in the outcome variables. However, a certain difference can be highlighted between models 1 and 2 regarding the composition of the profiles (fig. 1). In particular, the vulnerable profile was indicated by higher levels of mourning, lower perceived health, and lower life satisfaction in the constrained model than in the unconstrained model. Thus, the vulnerable profile classifies respondents in a condition of higher psychological vulnerability. Its estimated size was indeed smaller than the one in model 1. Also, the profile of the resigned ones was slightly different in the constrained model. Resigned ones in model 2 were indicated by a slightly higher self-perceived health but a lower life satisfaction than in the previous model.

In a further step, we tested our hypothesis of upward change by investigating whether the transitions between the profiles were unidirectional, i.e., from maladapted profiles to more resilient ones. To test this, model 3 excluded the possibility of back steps by constraining to 0 all backwards transitions. The model's fit (BIC index $=$ $6,542.65$, entropy $=0.91$ ) indicated that model 3 fit the data better than the previous models, providing support for the stage hypothesis. In line with our expectations that upward change would more likely occur in the three profiles with poor adaption, the model only showed transitions from the three lowest profiles to the higher ones. 
The copers and resilients were stable across time, supporting the hypothesis of stability in the more adapted profiles.

Finally, to further investigate the hypothesis of upward change, model 4 tested whether transitions can only happen between contiguous profiles. The model was estimated by constraining to 0 all transitions but those to the nearest profile. The model's fit (BIC index $=6,548.09$, entropy $=0.90)$ suggested that this model was better than model 2 but not model 3 . Consequently, model 3 was retained for further analyses on distal variables.

\section{Differences between Transition Patterns}

Following the procedure described in the analytical strategy section, differences between transition patterns were explored. Given the relatively small number of observations, some transition cells were empty (e.g., from vulnerables to copers), and in some other cases the number of observations within each transition was too small to use statistical parametric tests. For this reason, we decided to adopt a nonparametric strategy. Cohen's $d$ [38] was calculated to evaluate the size of the difference. Transitions with only one respondent are reported but not commented.

\section{Sociodemographics and Stressors}

As shown in table 3, in general, respondents who remained in the same profile did not differ from those who moved to a more resilient profile when considering gender. Regarding age, the resigned ones at $\mathrm{T} 1$ who were classified as copers in T2 were marginally older than the resigned ones who did not change profiles $(d=0.29)$. Age did not differ between stable and upward change patterns in other profiles $(d<0.1)$. Respondents moving from the resigned to the copers profile were also more likely to have recovered from the breakup of a longer relationship than those who remained in the resigned profile $(d=$ 1.07). This result was also replicated when controlling for the respondents' age, given that older respondents are more likely to have lived in longer relationships (results are not reported). Time also played an important and counterintuitive role in adaptation. The malcontents and resigned ones that had moved to the coper profile were characterized by less time since their breakup than those respondents who remained in the same profiles $(d=0.42$ and $d=0.31$, respectively). In addition, both the malcontents and resigned ones moving to the copers' profile were prompting lower levels of satisfaction with the former relationship at T2 than those who remained in the same profile. The difference was marginal for the malcontents

Trajectories of Adaptation to Marital Breakup

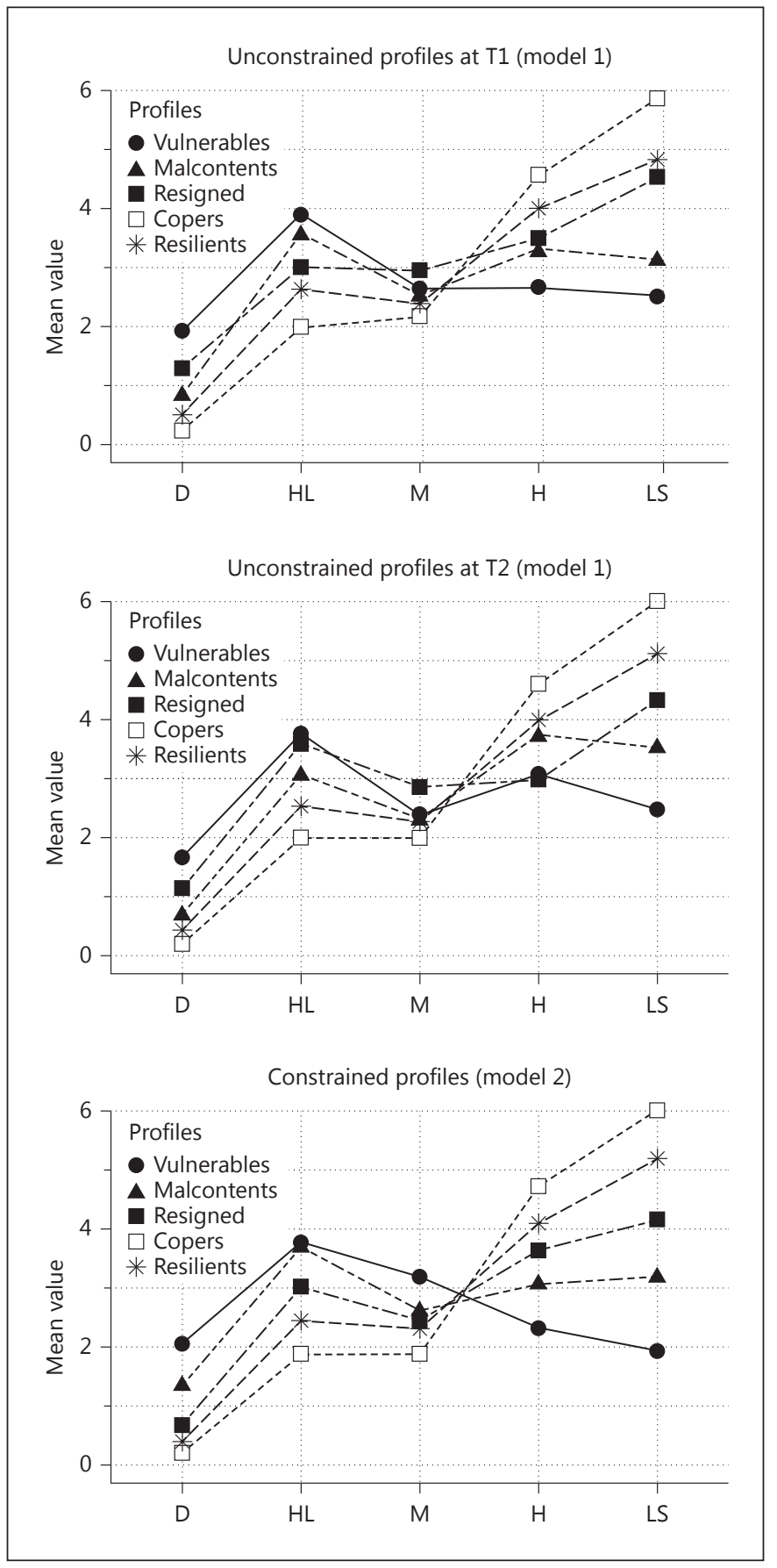

Fig. 1. Uncentered means of the T1 and T2 models and the measurement invariance model. $\mathrm{D}=$ Depression; $\mathrm{HL}=$ hopelessness; $\mathrm{M}=$ mourning; $\mathrm{H}=$ health; $\mathrm{LS}=$ life satisfaction.

( $d=0.10)$, but large for the resigned $(d=0.78)$. Against our expectations, no important differences in the perceived financial situation at T1 were associated with any of the transition patterns. 
Table 3. Means of sociodemographic and relationship variables for each transition pattern

\begin{tabular}{|c|c|c|c|c|c|c|}
\hline Variable & Profile & $\begin{array}{l}\text { Vulner }_{\mathrm{T} 2} \\
\text { mean } \pm \text { SE (n) }\end{array}$ & $\begin{array}{l}\text { Malcon }_{\mathrm{T} 2} \\
\text { mean } \pm \text { SE (n) }\end{array}$ & $\begin{array}{l}\operatorname{Resign}_{\mathrm{T} 2} \\
\text { mean } \pm \text { SE (n) }\end{array}$ & $\begin{array}{l}\text { Copers }_{\mathrm{T} 2} \\
\text { mean } \pm \text { SE (n) }\end{array}$ & $\begin{array}{l}\operatorname{Resili}_{\mathrm{T} 2} \\
\text { mean } \pm \mathrm{SE}(\mathrm{n})\end{array}$ \\
\hline Age & $\begin{array}{l}\text { Vulner }_{\mathrm{T} 1} \\
\text { Malcon }_{\mathrm{T} 1} \\
\text { Resign }_{\mathrm{T} 1} \\
\text { Copers }_{\mathrm{T} 1} \\
\text { Resili }_{\mathrm{T} 1}\end{array}$ & $54.25 \pm 3.38(4)$ & $55.53 \pm 1.24(28)$ & $\begin{array}{l}53.8 \pm 13.46(3) \\
56.05 \pm 6.44(6) \\
56.34 \pm 1.14(53)\end{array}$ & $\begin{array}{l}49.84 \pm 9.41(4) \\
59.41 \pm 3.92(16) \\
55.46 \pm 0.54(131)\end{array}$ & $\begin{array}{l}50.11 \pm 491.39(1) \\
50.95 \pm 133.71(1) \\
54.09 \pm 0.77(61)\end{array}$ \\
\hline Financial situation & $\begin{array}{l}\text { Vulner }_{\mathrm{T} 1} \\
\text { Malcon }_{\mathrm{T} 1} \\
\text { Resign }_{\mathrm{T} 1} \\
\text { Copers }_{\mathrm{T} 1} \\
\text { Resili }_{\mathrm{T} 1}\end{array}$ & $2.29 \pm 0.17$ & $2.06 \pm 0.13(24)$ & $\begin{array}{l}2.26 \pm 0.20(3) \\
2.96 \pm 1.33(7) \\
2.03 \pm 0.1(59)\end{array}$ & $\begin{array}{l}1.98 \pm 3.82(4) \\
1.05 \pm 34.57(0) \\
1.98 \pm 0.04(156)\end{array}$ & $\begin{array}{l}1.99 \pm 50.92(1) \\
2.93 \pm 1.66(1) \\
1.75 \pm 0.05(49)\end{array}$ \\
\hline $\begin{array}{l}\text { Length of former } \\
\text { relationship }\end{array}$ & $\begin{array}{l}\text { Vulner }_{\mathrm{T} 1} \\
\text { Malcon }_{\mathrm{T} 1} \\
\text { Resign }_{\mathrm{T} 1} \\
\text { Copers }_{\mathrm{T} 1} \\
\text { Resili }_{\mathrm{T} 1}\end{array}$ & $28.47 \pm 3.55$ & $25.17 \pm 1.26(28)$ & $\begin{array}{l}27.47 \pm 4.12(3) \\
25.92 \pm 7.18(6) \\
25.74 \pm 0.98(52)\end{array}$ & $\begin{array}{l}24.66 \pm 9.24(4) \\
34.13 \pm 2.69(14) \\
25.97 \pm 0.61(132)\end{array}$ & $\begin{array}{c}22.57 \pm 284.32(1) \\
27.1 \pm 82.48(1) \\
24.62 \pm 0.93(63)\end{array}$ \\
\hline Years since divorce & $\begin{array}{l}\text { Vulner }_{\mathrm{T} 1} \\
\text { Malcon }_{\mathrm{T} 1} \\
\text { Resign }_{\mathrm{T} 1} \\
\text { Copers }_{\mathrm{T} 1} \\
\text { Resili }_{\mathrm{T} 1}\end{array}$ & $1.05 \pm 1.70$ & $3.01 \pm 0.35(28)$ & $\begin{array}{l}2.75 \pm 0.81(3) \\
3.58 \pm 2.39(6) \\
2.72 \pm 0.26(53)\end{array}$ & $\begin{array}{l}1.75 \pm 3.86(4) \\
1.86 \pm 1.13(16) \\
3.06 \pm 0.17(134)\end{array}$ & $\begin{array}{l}1.18 \pm 139.87(1) \\
3.24 \pm 13.88(1) \\
3.02 \pm 0.21(58)\end{array}$ \\
\hline
\end{tabular}

Empty cells represent transitions with no respondents; $\mathrm{n}$ is the estimated most likely classification. Vulner $=$ Vulnerables; Malcon = malcontents; Resign = resigned ones; Resili = resilients. T1 and T2 refer to time 1 and time 2, respectively.

\section{Intrapersonal Resources}

With the exception of the malcontents passing to copers, all other respondents who improved their adaptation pattern had lower levels of neuroticism as hypothesized (table 4). The effect was particularly large for the vulnerables and malcontents moving to the resigned $(d=0.85$ and $d=1.54$, respectively), and for the resigned moving to copers $(d=0.76)$. In line with previous findings, extraversion was higher in respondents who were classified into more resilient profiles at $\mathrm{T} 2$, with the exception of vulnerables moving to the resigned, who were less extraverted than those who remained in the vulnerable profile $(d=0.85)$. On the other hand, individuals moving from vulnerables to the resigned had higher scores of openness $(d=0.90)$. Other differences between transition patterns of openness were marginal $(d<0.20)$. Yet, in line with our expectations, trait resilience was lowest for the vulnerables who remained in the same group of adaptation, and highest among the bestadapted group of resilients. Trait resilience was higher for the vulnerables $(d=1.03)$ and for the malcontents $(d=$ $1.42)$ moving to the resigned and to copers $(d=0.62)$, and finally for the resigned moving to copers $(d=0.45)$.

Concerning personal growth, the perception of having new life perspectives was more pronounced among the malcontents who moved upward (to the resigned, $d=0.63$; to the copers, $d=0.28$ ), but null for the resigned who moved 
Table 4. Means of intrapersonal resources for each transition pattern

\begin{tabular}{|c|c|c|c|c|c|c|}
\hline Variable & Profile & $\begin{array}{l}\text { Vulner }_{\mathrm{T} 2} \\
\text { mean } \pm \text { SE (n) }\end{array}$ & $\begin{array}{l}\text { Malcon }_{\mathrm{T} 2} \\
\text { mean } \pm \text { SE (n) }\end{array}$ & $\begin{array}{l}\text { Resign }_{\mathrm{T} 2} \\
\text { mean } \pm \text { SE (n) }\end{array}$ & $\begin{array}{l}\text { Copers }_{\mathrm{T} 2} \\
\text { mean } \pm \text { SE (n) }\end{array}$ & $\begin{array}{l}\text { Resili }_{\mathrm{T} 2} \\
\text { mean } \pm \text { SE (n) }\end{array}$ \\
\hline $\mathrm{BFI}$ - extraversion ${ }_{\mathrm{T} 2}$ & $\begin{array}{l}\text { Vulner }_{\mathrm{T} 1} \\
\text { Malcon }_{\mathrm{T} 1} \\
\text { Resign }_{\mathrm{T} 1} \\
\text { Copers }_{\mathrm{T} 1} \\
\text { Resili }_{\mathrm{T} 1}\end{array}$ & $3.36 \pm 0.4(3)$ & $2.31 \pm 0.24(29)$ & $\begin{array}{l}2.69 \pm 0.83(3) \\
4.48 \pm 1.66(3) \\
3.13 \pm 0.16(61)\end{array}$ & $\begin{array}{l}2.68 \pm 2.13(4) \\
3.85 \pm 0.84(10) \\
3.44 \pm 0.10(129)\end{array}$ & $\begin{array}{l}3.06 \pm 195.75(1) \\
3.46 \pm 178.56(1) \\
4.2 \pm 9.60(2) \\
4.05 \pm 0.17(62)\end{array}$ \\
\hline $\mathrm{BFI}$ - openness T2 $_{\mathrm{T}}$ & $\begin{array}{l}\text { Vulner }_{\mathrm{T} 1} \\
\text { Malcon }_{\mathrm{T} 1} \\
\text { Resign }_{\mathrm{T} 1} \\
\text { Copers }_{\mathrm{T} 1} \\
\text { Resili }_{\mathrm{T} 1}\end{array}$ & $3.24 \pm 0.35(4)$ & $3.48 \pm 0.23(28)$ & $\begin{array}{l}4.47 \pm 1.08(3) \\
3.09 \pm 0.60(6) \\
3.82 \pm 0.17(70)\end{array}$ & $\begin{array}{l}3.93 \pm 1.98(3) \\
2.37 \pm 1.45(6) \\
3.62 \pm 0.10(125)\end{array}$ & $\begin{array}{l}4.99 \pm 474.34(1) \\
4.84 \pm 99.68(1) \\
3.95 \pm 3.88(2) \\
4.1 \pm 0.16(59)\end{array}$ \\
\hline Trait resilience $_{\mathrm{T} 2}$ & $\begin{array}{l}\text { Vulner }_{\mathrm{T} 1} \\
\text { Malcon }_{\mathrm{T} 1} \\
\text { Resign }_{\mathrm{T} 1} \\
\text { Copers }_{\mathrm{T} 1} \\
\text { Resili }_{\mathrm{T} 1}\end{array}$ & $3.81 \pm 0.18$ & $4.56 \pm 0.09(30)$ & $\begin{array}{l}5.9 \pm 1.99(3) \\
5.73 \pm 0.99(5) \\
5.3 \pm 0.13(56)\end{array}$ & $\begin{array}{l}4.97 \pm 1.73(2) \\
5.53 \pm 0.51(15) \\
5.65 \pm 0.08(126)\end{array}$ & $\begin{array}{l}6.48 \pm 32.01(1) \\
6.65 \pm 5.91(3) \\
6.27 \pm 0.14(63)\end{array}$ \\
\hline $\begin{array}{l}\text { Growth }_{\mathrm{T} 2}- \\
\text { new life perspectives }\end{array}$ & $\begin{array}{l}\text { Vulner }_{\mathrm{T} 1} \\
\text { Malcon }_{\mathrm{T} 1} \\
\text { Resign }_{\mathrm{T} 1} \\
\text { Copers }_{\mathrm{T} 1} \\
\text { Resili }_{\mathrm{T} 1}\end{array}$ & $3.97 \pm 1.33(4)$ & $3.81 \pm 0.40(28)$ & $\begin{array}{l}2.61 \pm 1.86(4) \\
4.96 \pm 1.88(5) \\
4.21 \pm 0.30(51)\end{array}$ & $\begin{array}{l}4.25 \pm 4.48(4) \\
4.35 \pm 1.44(22) \\
3.89 \pm 0.16(125)\end{array}$ & $\begin{array}{l}5.84 \pm 86.52(1) \\
4.67 \pm 61.49(1) \\
4.09 \pm 0.19(63)\end{array}$ \\
\hline
\end{tabular}

Empty cells represent transitions with no respondents; $\mathrm{n}$ is the estimated most likely classification. Vulner = Vulnerables; Malcon = malcontents; Resign = resigned ones; Resili = resilients. T1 and T2 refer to Time 1 and Time 2, respectively.

to copers $(d=0.03)$ and smaller for the vulnerables moving to the resigned $(d=0.41)$. No difference regarding spirituality was observed between respondents who stayed in the same profile and those who moved upward $(d<0.20$, and $d=0.28$ for the malcontents moving to copers). An acquired sense of personal strength characterized the malcontents moving to the resigned $(d=0.63)$ and copers $(d=0.43)$. No differences were connected with the other transitions.

Trajectories of Adaptation to Marital Breakup

\section{Discussion}

The purpose of this study was to explore trajectories of psychological adaptation to marital breakup, and to examine the variables that account for recovery or chronicity in terms of intrapersonal resources, relationship variables, and sociodemographic variables. Our study expands existing research in two ways: first, we focus on 
individuals aged 55 years and older who had been divorced after a long marriage. Despite the increase in 'gray divorce', little is known about the psychological adaptation to this critical life event after many years of marriage. Second, in contrast to most research conducted so far, we took into account multiple aspects of well-being, which allows a more comprehensive view of psychological adaptation.

The results show that our expectations were only partially confirmed. There was indeed a higher probability for some individuals with lower adaptation at T1 to make an upward change to better-adapted groups at T2. However, most of the changes found occurred within the maladapted groups, meaning that they were still struggling with adaptation 2 years later. In fact, a substantial number of individuals of the three initially poorly adapted groups still remained in the same profile (i.e., $41 \%$ of the vulnerables, $57.6 \%$ of the malcontents, and $68 \%$ of the resigned). These results underline other findings $[14,15]$, demonstrating that a minority of divorcees still remains vulnerable even years after the event.

The most significant improvement resulted for those individuals who switched from one of the maladapted groups to the well-adapted group of 'copers'. These individuals succeeded in getting out of a state of resignation, vulnerability, and dissatisfaction and showed better average scores in the different indicators of adaption 2 years later. Therefore, we are particularly interested in this group of 'successful' individuals when investigating factors that account for improvement or stability.

As expected, the groups of copers and resilients remained stable regarding their psychological adaption to marital breakup throughout the 2 years. However, it is noteworthy that there was almost no upward change from the copers to the resilient group. It can be assumed that the copers have reached their best possible level of functioning, which is still lower than that of the resilients. The latter are thought to have a higher baseline of psychological functioning and the most favorable personality traits for adaptation in case of critical life events. In fact, individuals from the resilient group had the highest scores in trait resilience, openness, and extraversion and the lowest score in neuroticism in comparison with all other groups.

The question of which factors account for improvement was the second issue of this research. Considering the research gap regarding adaptation to 'gray divorce', the role of age as well as the length of the former relationship was of major interest. Our results reveal that both variables were relevant for an upward change. Even though we did not have any expectations in this regard, this result appears to be somewhat contrary to the common assumption that a marital breakup is more incisive for older people and the long-term married. In fact, our results show that the upward change from the resigned group to the copers was associated with a longer relationship and older age compared with those individuals who remained in the same profile. A possible interpretation could be that a marital breakup after many years of marriage following a phase of resignation can indeed be perceived as a chance to find alternative ways of dealing with the new situation. We know from the literature that older age is associated with better strategies to equilibrate one's well-being [39]. In addition, it can be assumed that a long-term marriage does not necessarily imply a good relationship. In fact, what our results also reveal is that those groups of individuals (malcontents and resigned) moving to the better-adapted group of copers reported lower scores in 'satisfaction with the former relationship'. This result is in line with our expectations and with other findings showing that people from high-distress marriages have less difficulty in adapting than those from lowdistress ones [19]. It can be assumed that leaving an unsatisfying marriage represents a relief and a necessary step for one's own well-being.

However, in contrast to our expectations, more time since divorce did not account for a better adaptation. In fact, just the contrary was the case, at least for the malcontent and resigned groups, in which the upward change was associated with a more recent divorce. A possible interpretation could be that dissatisfaction as a rather cognitive dimension of well-being is a strong incentive to actively change things. This contrasts other ways of adapting to marital breakup such as vulnerability and resignation, which tend to get stuck in an early stage of adaptation and show long-term difficulties in recovery.

Gender and financial resources did not account for any of the upward changes between the profiles. Interestingly, financial resources, which was a discriminant variable among the five groups at T1 (better financial situation for the groups of the better adapted), did not play a significant role when looking at adaptation between $\mathrm{T} 1$ and T2. This finding suggests that financial concerns are decisive in dealing with the manifold changes directly following a marital breakup [40]; however, as time passes, other resources become more important.

Intrapersonal resources were expected to be strongly related to upward changes. This assumption was only partially confirmed. In fact, individuals who made an upward change (resigned) to a better-adapted group showed 
lower scores in neuroticism than those who remained in the same profile. Extraversion was higher in respondents who were classified into more resilient profiles at T2; however, it did not account for upward change to the well-adapted groups.

Trait resilience resulted in being a strong discriminant variable between groups: it was lowest for the stable vulnerables and highest in the best-adapted group (resilients); in addition, it was significantly higher for the resigned moving to being copers. This finding is in line with the literature, suggesting that trait resilience may be seen as contributing, among other factors, to resilient behavior as an outcome $[13,21,41]$.

Finally, out of the three indicators of personal growth, only personal strength was related to upward changes, i.e., for the malcontents moving to the group of copers. This result supports the assumption that believing in positive changes is a possible and helpful adaptation strategy even after a marital breakup in later years [42].

Overall, our study expands existing research in various ways: while it underlines findings about heterogeneity in psychological adaptation to divorce, it shows that the amount of resilients is smaller than reported by others [15]. In addition, it provides evidence that there is only a modest chance of recovery for the maladapted groups, which can be explained by personality traits being the strongest factor for group allocation. Finally, the most innovative contribution of this study is that advancing age and longer duration of marriage were shown not to play as negative a role as could be expected - just the opposite.
This supports existing research that in general older individuals have better strategies for regulating well-being. Our findings also have strong practical implications: even though personality factors, which are thought to be rather time-stable, are the strongest discriminating factors between the groups of adaptation, it seems that there is still potential for change with advancing age. This knowledge is essential for prevention and intervention measures. Such interventions should not only focus on the treatment of psychological impairment and encourage social interactions; they should also provide further opportunities to train and develop skills associated with trait resilience.

Although our findings offer important insights, there is a methodological limitation to be considered, namely the small sample sizes of some transition cells, which reduces the results' explanatory power. Given the lack of data regarding divorce after long-term marriage, it will be important for future research (1) to gather more data from this specific age group and to compare it with younger ones, and (2) to refine our understanding of the factors that contribute to the different trajectories of adjustment over time.

\section{Acknowledgments}

The authors were supported by a grant from the Swiss National Science Foundation (project No. 125770) awarded to Pasqualina Perrig-Chiello. The project 'Relationships in later life' is part of the National Centre of Competence in Research LIVES 'Overcoming vulnerability over life course'.

\section{References}

1 Brown A, Jones JM: Separation, divorce linked to sharply lower well-being. Gallup, 2012. http://www.gallup.com/poll/154001/ Separation-Divorce-Linked-Sharply-LowerWellbeing.aspx (accessed June 4, 2015).

2 Amato PR: Research on divorce: continuing trends and new developments. J Marriage Fam 2010;72:650-666

3 Clark AE, Georgellis Y: Back to baseline in Britain: adaptation in the British household panel survey. Economia 2013;80:496-512.

4 Bonanno GA: Loss, trauma, and human resilience: have we underestimated the human capacity to thrive after extremely aversive events? Am Psychol 2004;59:20-28.

5 Johnson DR, Wu J: An empirical test of crisis, social selection, and role explanations of the relationship between marital disruption and psychological distress: a pooled time-series analysis of four-wave panel data. J Marriage Fam 2002;64:211-224.
6 Perrig-Chiello P, Hutchison S, Morselli D: Patterns of psychological adaptation to divorce after a long-term marriage. J Soc Pers Relat 2015;32:386-405.

7 Brown SL, Lin IF: The gray divorce revolution: rising divorce among middle-aged and older adults, 1990-2010. J Gerontol B Psychol Sci Soc Sci 2012;67B:731-741.

8 Swiss Federal Office of Statistics: Durchschnittliche Ehedauer bei der Scheidung. Bern, 2014. http://www.bfs.admin.ch/bfs/ portal/de/index/themen/01/06/blank/ key/06/04.html (accessed August 8, 2015).

9 Wang H, Amato PR: Predictors of divorce adjustment: stressors, resources, and definitions. J Marriage Fam 2000;62:655-668.

10 Pudrovska T, Carr D: Psychological adjustment to divorce and widowhood in mid- and later life: do coping strategies and personality protect against psychological distress? Adv Life Course Res 2008;13:283-317.
11 Schoenborn CA: Marital status and health: United States, 1999-2002. Adv Data 2004;15: $1-32$.

12 Bookwala J, Marshall KI, Manning SW: Who needs a friend? Marital status transitions and physical health outcomes in later life. Health Psychol 2014;33:505-515.

13 Bonanno GA, Mancini AD: The human capacity to thrive in the face of potential trauma. Pediatrics 2008;121:369-375.

14 Hetherington EM: Intimate pathways: changing patterns in close personal relationships across time. Fam Relat 2003;52:318-331.

15 Mancini AD, Bonanno GA, Clark AE: Stepping off the hedonic treadmill: individual differences in response to major life events. J Individ Differ 2011;32:144-152.

16 Infurna FJ, Luthar SS: Resilience to major life stressors is not as common as thought. Perspect Psychol Sci, in press. 
17 Amato PR: The consequences of divorce for adults and children. J Marriage Fam 2000;62: 1269-1287.

18 Braver SL, Shapiro JR, Goodman M: The consequences of divorce for parents; in Fine MA, Harvey JH (eds): Handbook of Divorce and Relationship Dissolution. New Jersey, Erlbaum, 2006, pp 313-337.

19 Amato PR, Hohmann-Marriott B: A comparison of high- and low-distress marriages that end in divorce. J Marriage Fam 2007;69:621638.

20 Waite LJ, Luo Y, Lewin AC: Marital happiness and marital stability: consequences for psychological well-being. Soc Sci Res 2009;38: 201-212.

21 Ong AD, Bergeman C, Bisconti TL, Wallace KA: Psychological resilience, positive emotions, and successful adaptation to stress in later life. J Pers Soc Psychol 2006;91:730-749.

22 Tashiro T, Frazier P: 'I'll never be in a relationship like that again': personal growth following romantic relationship breakups. Pers Relatsh 2003;10:113-128.

23 Tedeschi RG, Park CL, Calhoun LG: Posttraumatic Growth: Positive Changes in the Aftermath of Crisis. Mahwah, Erlbaum, 1998.

24 Luhmann M, Hofmann W, Eid M, Lucas RE: Subjective well-being and adaptation to life events: a meta-analysis. J Pers Soc Psychol 2012;102:592-615.

25 Schumacher J: SWLS - satisfaction with life scale; in Schumacher J, Klaiberg A, Brähler E (eds): Diagnostische Verfahren zu Lebensqualität und Wohlbefinden. Göttingen, Hogrefe, 2003, pp 305-309.

26 Hautzinger M, Bailer M: Allgemeine Depressions Skala. Manual. Göttingen, Beltz Test GmbH, 1993.
27 Krampen G: Skalen zur Erfassung von Hoffnungslosigkeit (H-Skalen). Deutsche Bearbeitung und Weiterentwicklung der H-Skala von Aaron T. Beck. Handanweisung. Göttingen, Hogrefe, 1994.

28 Rammstedt B, John OP: Measuring personality in one minute or less: a 10-item short version of the Big Five Inventory in English and German. J Res Pers 2007;41:203-212.

29 Schumacher J, Leppert K, Gunzelmann T, Strauss B, Brähler E: The resilience scale - a questionnaire to assess resilience as a personality characteristic. Z Klin Psychol Psychiatr Psychother 2005;53:16-39.

30 Maercker A, Langner R: Persönliche Reifung durch Belastungen und Traumata: Ein Vergleich zweier Fragebogen zur Erfassung selbstwahrgenommener Reifung nach traumatischen Erlebnissen. Diagnostica 2001;47: 153-162.

31 Nylund KL, Asparouhov T, Muthen BO: Deciding on the number of classes in latent class analysis and growth mixture modeling: a Monte Carlo simulation study. Struct Equ Modeling 2007;14:535-569.

32 Lanza ST, Tan X, Bray BC: Latent class analysis with distal outcomes: a flexible modelbased approach. Struct Equ Modeling 2013; 20:1-26.

33 Clark S, Muthén B: Relating latent class analysis results to variables not included in the analysis, 2009. Unpublished paper. http:// www.statmodel.com/download/relatinglca. pdf (accessed August 15, 2015).
34 Nylund-Gibson K, Grimm R, Quirk M, Furlong M: A latent transition mixture model using the three-step specification. Struct Equ Modeling 2014;21:439-454.

35 Asparouhov T, Muthén B: Auxiliary variables in mixture modeling: a 3-step approach using Mplus: Mplus Web Notes No 15, 2013. https://www.statmodel.com/download/webnotes/webnote15.pdf (accessed September 4, 2015).

36 Hallquist M, Wiley J: MplusAutomation: automating Mplus model estimation and interpretation. R package version 0.6-3, 2014 https://cran.r-project.org/web/packages/ MplusAutomation/index.html (accessed August 20, 2015).

37 Hipp JR, Bauer DJ: Local solutions in the estimation of growth mixture models. Psychol Methods 2006;11:36-53.

38 Cohen J: Statistical Power Analysis for the Behavioral Sciences. Hillsdale, Erlbaum, 1988 ed 2.

39 Hamarat E, Thompson D, Steele D, Matheny K, Simons C: Age differences in coping resources and satisfaction with life among middle-aged, young-old, and oldest-old adults. J Genet Psychol 2002;163:360-367.

40 Knox D, Corte U: 'Work it out/see a counselor': advice from spouses in the separation process. J Divorce Remarriage 2007;48:79-90.

41 Windle G, Bennett KM, Noyes J: A methodological review of resilience measurement scales. Health Qual life Outcomes 2011;9:118.

42 Lamela D, Figueiredo B, Bastos A, Martins H: Psychometric properties of the Portuguese version of the posttraumatic growth inventory short form among divorced adults. Eur J Psychol Assess 2014;30:3-14. 